\title{
Alucinando uma pandemia: ensaio sobre as disputas pela realidade da Covid-19
}

Hallucinating a pandemic: essay on disputes over the reality of COVID-19

\author{
Alexandre Branco-Pereira' \\ https://orcid.org/0000-0002-3513-5728 \\ alebrancop@gmail.com \\ I Universidade Federal de São Carlos - São Carlos, SP, Brasil
}




\title{
Resumo
}

O primeiro objetivo deste ensaio é delinear os fenômenos tidos como alucinatórios, essencialmente indistinguíveis da realidade, apresentando a forma como a definição do que chamo de mundo-em-si, externo ao indivíduo e alheio às simbolizações que se lhe podem atribuir, constitui-se como uma disputa pela própria substância da realidade. Discursos da saúde mental tornam-se privilegiados para a definição sobre quais mundos existem ou não, e a imanência da realidade é constante objeto de disputa. O segundo objetivo é demonstrar o argumento através da análise do fenômeno específico da gestão estatal da pandemia de Covid-19 no Brasil, descrevendo como o discurso pró-ciência, inicialmente utilizado para legitimar quarentenas restritivas, passou paulatinamente a justificar as reaberturas e flexibilizações em supostos cenários de estabilidade no número de mortos e de novos casos. Este movimento lançou vozes dissonantes a uma condição análoga à experimentação alucinatória da realidade.

Palavras-chave: alucinação; realidade; Covid-19; mundo-em-si.

\begin{abstract}
The first objective of this essay is to delineate hallucinatory phenomena, essentially indistinguishable from reality, presenting the way in which the definition of what I call the world-in-itself, external to the individual and oblivious to the symbolizations that can be attributed to it, is constituted as a dispute for the very substance of reality. Mental health discourses become privileged for the definition of which worlds exist or not, and the immanence of reality is a constant object of dispute. The second objective is to demonstrate the argument through the analysis of the specific phenomenon of the state management of the COVID-19 pandemic in Brazil, describing how the pro-science discourse, initially used to legitimize restrictive quarantines, gradually started to justify the reopening and flexibilization in supposed stability scenarios of the number of deaths and new cases. This movement put dissonant voices to a condition analogous to the hallucinatory experimentation of reality.
\end{abstract}

Keywords: hallucination; reality; world-in-itself; COVID-19. 


\section{Introdução ${ }^{1}$}

O objetivo central deste ensaio é refletir sobre os processos de construção e disputa pela realidade calcadas na premissa da existência de um mundo-em-si que transcendem às meras ficções humanas e disputas político-ideológicas mundanas. Tal movimento soergue também a ideia de um conhecimento científico enquanto mero descritor de uma natureza autoevidente, imune às crenças humanas, a juízos de valor e, sobretudo, não implicada nas disputas políticas que a acionam enquanto fonte de legitimidade e autoridade. Erige-se, assim, um conhecimento que se adjetiva enquanto neutro, e a neutralidade surge como argumento político incontornável (Branco-Pereira, 2019, 2020a, 2020c).

Busco, na primeira parte do ensaio, delinear uma antropologia e uma filosofia das alucinações, apontando para como as divisões entre a experiência tida como real e a alucinatória são, por vezes, arbitrárias e enraizadas no estabelecimento de assimetrias sobre quais agentes têm poder de definir o que existe, ou o que é, de fato, a natureza real das coisas, alheia às simbolizações passíveis de lhe serem atribuídas. Em um segundo momento, procuro apresentar os movimentos realizados por autoridades públicas, agentes do Estado e da imprensa que versam sobre a defesa ou não de quarentenas restritivas como política de mitigação dos efeitos deletérios acarretados pela pandemia de Covid-19, e em como esse movimento, coreografado entre esses diversos atores, lançou paulatinamente as vozes dissonantes a uma condição de experimentação da realidade análoga à alucinatória, ou seja, de percepção (ou fabricação) de um mundo descontinuado dos ícones fornecidos pela imanência da realidade: em outras palavras, um mundo que não pode existir, fruto de uma apreensão equivocada da realidade autoevidente.

1 Este trabalho integra o projeto "A Covid-19 no Brasil: análise e resposta aos impactos sociais da pandemia entre profissionais de saúde e população em isolamento" (Convênio Ref.: 0464/20 Finep/UFRGS). A pesquisa é desenvolvida pela Rede Covid-19 Humanidades MCTI e integra o conjunto de ações da Rede Vírus MCTI financiadas pelo Ministério da Ciência, Tecnologia e Inovações para o enfrentamento da pandemia. 


\section{Nem otimista, nem pessimista: realista}

Em primeiro de julho de 2020, o estado de São Paulo, Brasil, ultrapassou as 15 mil mortes por Covid-19. Àquele dia, o mesmo estado totalizava 289.935 casos confirmados da doença. A despeito dos números, o governador do estado, João Doria - que até então vocalizava defesas apaixonadas da ciência e das "orientações da Organização Mundial de Saúde" e antagonizava o presidente brasileiro, Jair Bolsonaro, notório sabotador dos esforços para conter o avanço da pandemia - convocou uma coletiva de imprensa para anunciar que São Paulo atingira o chamado platô, o que indicava uma estabilidade de casos e de mortes. $\mathrm{O}$ anúncio das mortes significava que centenas de vidas haviam sido, na realidade, poupadas em decorrência das medidas adotadas pelo governo estadual, $\mathrm{e}$ que o estado estava pronto para uma "quarentena heterogênea" e "inteligente". O plano, denominado de Plano São Paulo, dividia as regiões do estado em cores que gradavam entre o azul (normal controlado) e o vermelho (alerta máximo), orientando uma reabertura da economia que, entretanto, "não era uma flexibilização" da quarentena, nas palavras de João Doria. Ao final, o governador disse que não queria ser "nem otimista e nem pessimista", mas "realista": estava, ali, exposta a realidade despida de qualquer crença matizante que a pudesse enviesar; a natureza em si mesma.

Simultaneamente, reportagens jornalísticas sobre uma condição psicológica denominada síndrome da cabana, descrita como um medo irracional de sair de casa e de conviver com outras pessoas, preencheram paulatinamente os noticiários. A condição, descrita pela primeira vez no início do século XX, ganhou relevo novamente enquanto descrição do sofrimento psicológico relativo ao caráter ansiogênico causado pelo isolamento forçado em decorrência da pandemia, especialmente ligado aos planos de reabertura colocados em moção no Brasil a partir de junho e julho de 2020. Em um levantamento realizado no Google, ${ }^{2}$ nota-se o crescimento: entre março e meados de agosto de 2020, quando a primeira versão deste ensaio foi escrita, foram publicadas ao menos 30 matérias jornalísticas destinadas à descrição da síndrome, sendo uma em março, duas em maio, cinco em junho, 15 em julho e seis em agosto (até o dia 11/08).

2 Termos de busca: "síndrome da cabana". Artigos opinativos foram descartados, bem como aqueles de veículos de comunicação de fora do Brasil. 
Atualizada, a síndrome ganhou o nome de FOGO - fear of going out-, e passou a referir-se à resposta emocional considerada desproporcional que determinadas pessoas apresentavam diante das reaberturas da economia pós-quarentena.

Este ensaio tem dois objetivos. O primeiro é delinear os fenômenos tidos como alucinatórios, apresentando a forma como a definição do que chamo de mundo-em-si, externo ao indivíduo e alheio às simbolizações que se lhe podem atribuir, constitui-se como uma disputa pela própria substância da realidade. Assim, discursos sobre a saúde mental tornam-se perspectivas privilegiadas de definição sobre quais mundos existem ou não (Branco-Pereira, 2018, 2019, 2020a, 2020b, 2020c), e a imanência da realidade é ela mesma constante objeto de disputa política. As alucinações, essencialmente indistinguíveis da realidade (Luhrmann, 2011; Seth, 2017), pois que quem alucina nunca sabe que o faz, tornam-se, assim, fenômenos políticos disputáveis. A construção de um mundo comum compartilhado, nos termos de Latour (2011a, 2011b, 2014), é eminentemente assimétrica e envolve a centralização do poder da tessitura da realidade - sinônimo, em determinada medida, de natureza - por determinados agentes privilegiados, como aqueles vinculados ao Estado e a determinadas disciplinas responsáveis pela construção do que se chama de saber científico, diametralmente oposto às lentes convexas das crenças, que enviesam o olhar sobre o mundo-em-si.

O segundo objetivo do ensaio é demonstrar o argumento por meio da análise do fenômeno específico da gestão estatal da pandemia de Covid-19 no Brasil, descrevendo como o discurso pró-ciência, inicialmente utilizado para legitimar quarentenas restritivas por parte de governos municipais e estaduais - em guerra, à época, contra o negacionismo do governo federal brasileiro - passou paulatinamente a justificar as reaberturas e flexibilizações em supostos cenários de estabilidade no número de mortos e de novos casos. Esse movimento lançou vozes dissonantes a uma condição análoga à experimentação psicótica da realidade, tornando o medo causado pelo fim da quarentena alucinatório, ou seja, uma "percepção, enquanto em estado consciente, na ausência de um estímulo externo" que tem as qualidades de uma "percepção real", ou seja, é "vívida, substancial e localizada em espaços externos objetivos" (Luhrmann, 2011, p. 72, tradução minha). Essa experimentação da realidade é tomada como exemplo dessa disputa: se, antes, esse medo era tido como justificável e legítimo diante de uma pandemia causada por um vírus potencialmente mortal e altamente 
contagioso, sendo incentivado por agentes estatais e supraestatais, além de membros da comunidade científica (Harper et al., 2020; Pakpour; Griffiths, 2020), como fator desejável de proteção individual e controle coletivo da pandemia, ele passa a ser uma experimentação psicológica (e, assim, eminentemente individual, biológica e, por que não, apolítica) protopatológica, pois que o estímulo externo está, sob essa perspectiva, ausente no mundo real unívoco.

\section{Alucinação: a construção do "real" e do mundo-em-si}

Se as causas de fenômenos alucinatórios são, desde perspectivas neurológicas, psiquiátricas ou psicológicas, múltiplas e variadas, alucinações, como brevemente pontuado no tópico anterior, são descritas como "a percepção de um objeto ou evento (por qualquer um dos cinco sentidos) na ausência de um estímulo externo" (Teeple; Caplan; Stern, 2009, p. 26, tradução minha). O estímulo externo - localizado em um mundo que está inequivocamente fora da unidade mental individual - é, portanto, pedra angular para a definição do que é ou não um fenômeno alucinatório: uma ilusão, por exemplo, diferencia-se de uma alucinação precisamente por esse fator, uma vez que, de acordo com a literatura psiquiátrica, uma ilusão é "uma percepção real [...] distorcida de alguma forma" (Chiu, 1989, p. 292, tradução minha, grifo meu). A existência de fenômenos considerados alucinatórios requer a existência de uma realidade objetiva e factual. Assim, um mundo externo ao indivíduo que existe independente do que se lhe agrega simbolicamente - neutro, portanto, à camada acessória de significados que se lhe atribuem - é requisito para que alucinações existam como fenômeno de percepção descontinuada dos ícones imanentes de realidade fornecidos pelo mundo, apreendidos pela captação sensorial disponibilizada pelo corpo e interpretados e traduzidos pelo aparato biológico neural. Duas naturezas, uma interna e outra externa (Descola, 2011), concorrem, portanto, para a percepção, a cognição e a experimentação do mundo-em-si, significado, em um momento posterior, de acordo com um arcabouço simbólico acessório que em nada lhe afeta a realidade.

A alucinação não reserva qualquer diferença de nível sensorial com a experimentação da realidade - o que possibilita a determinada corrente da neurociência, inclusive, argumentar que a própria realidade consciente é subproduto de processos alucinatórios (Seth, 2017). O traço diacrítico, portanto, 
das experiências tidas como reais seria a corroboração da percepção por meio de marcadores externos à unidade perceptiva ${ }^{3}$ que existem em si mesmos, de maneira independente e desconectados da percepção: perceber, no sentido de interpretar os ícones comunicativos enviados pelo mundo-em-si que permitem sua significação, não funda a realidade, apenas toma nota dela. Dessa forma, a camada simbólica aplicada sobre a realidade não lhe altera as propriedades: há uma dimensão transcendente aos fenômenos do mundo-em-si que lhe garantem a existência ainda que não haja ninguém para significá-la. Assim, a teoria das alucinações pretende resolver o paradoxo filosófico de Berkeley, uma vez que se uma árvore cai no meio de uma floresta sem que ninguém ouça o som de sua queda, ela continua, sim, existindo, pois a realidade da árvore ultrapassa a necessidade de percepção de outrem sobre o fenômeno. O mundo externo funda a realidade, ao passo que o mundo interno a confunde. Por outro lado, ver e ouvir uma árvore caindo sem que ela, enquanto mundo-em-si irredutível a si mesma, esteja de fato caindo não pode ser nada além de uma alucinação.

Tal divisão entre interno e externo é igualmente importante. Como argumentou Luhrmann (2011), definir se a fonte da experiência é interna (of the self) ou externa (not of the self) é crucial para a definição do que é ou não uma alucinação. Caso a fonte da percepção seja interna às "mentes" e aos "cérebros", ou seja, não compartilhada, produtora de um mundo eminentemente individual e descontinuado do mundo comum, ela será mais facilmente categorizável enquanto um fenômeno alucinatório: "está só na sua cabeça”, ou “é só você que vê" (Branco-Pereira, 2013). Entretanto, definir se um fenômeno sensorialmente ativado por um estímulo tido enquanto externo está, de fato, "lá", em um espaço externo objetivo (Chiu, 1989; Luhrmann, 2011), é uma tarefa que requer árbitros externos ao cérebro ou à mente individuais - é, portanto, da esfera da construção de um mundo compartilhado. Tal mundo não existe previamente à sua construção, como argumentou Latour (2011a, 2011b), uma vez que essa realidade é sempre alucinatória: se não há diferenças substanciais entre as percepções alucinatórias e as reais que não a existência do estímulo externo, é preciso aferir tal existência coletivamente, e a realidade é, pois, da esfera da construção comum.

3 Chamo de unidade perceptiva o compósito a que se referem a medicina e a psicologia, além das disciplinas contíguas, quando falam de cérebros, sistemas nervosos e mentes (ou psiquês). 
Stengers (2005) argumenta que os físicos, responsáveis por definir a realidade (física) como objetiva e transcendente às ficções humanas, igualavam os ataques a seu campo de conhecimento com ataques à própria racionalidade. Sob essa perspectiva, ou se estava de acordo ao que apresentavam enquanto realidade (física), ou se estaria não apenas contra os físicos, mas contra a própria razão (Stengers, 2005, p. 183-184). A definição da realidade a partir da elaboração de uma natureza externa, irredutível a si mesma e alheia aos significados que se lhe atribuem é um fenômeno cotidiano, e seu questionamento produz tensões e expõe assimetrias realçando que existem posições privilegiadas de definição do que é ou não real, e, assim, sobre quais mundos existem ou não.

Da mesma forma, portanto, que Bunzl (1996) formula ao tecer comentários sobre Franz Boas: a divisão marcada entre um mundo natural unívoco, cuja análise é da alçada das law-giving sciences, e uma infinidade de mundos particulares produzidos a partir da natureza multissimbólica (ou multicultural) da humanidade define a abordagem metodológica - eminentemente política e, por que não, ideológica - a ser adotada. Define-se também o que será universal, e o que será situado e contextual, com leis aplicáveis apenas a uma sorte limitada de eventos reduzidos a meras variações de uma base que os transcendem em escala e complexidade. Alucinações e realidade - ou mundos particulares versus mundo universal e unívoco - são apenas diferenciáveis por determinantes outros que via de regra remetem a assimetrias de poder e à centralização da possibilidade de tessitura do real.

\section{"O meu delírio é a experiência com coisas reais"4}

A síndrome da cabana é uma condição psicológica que remete ao medo desproporcional de sair de casa. A condição, descrita pela primeira vez no início do século XX, ganhou relevo novamente enquanto descrição do sofrimento psicológico (e potencialmente psiquiátrico, em uma divisão entre distúrbios de dimensão simbólica e aqueles de origem biológica, mais reais enquanto processos patológicos) relativo ao caráter ansiogênico causado pelo isolamento

4 Trecho da letra da canção “Alucinação”, lançada em 1976 por Belchior em álbum homônimo. 
forçado em decorrência da pandemia, especialmente ligado aos planos de reabertura colocados em moção no Brasil a partir de junho e julho de 2020 após meses de restrições à mobilidade e de fechamento de serviços considerados não essenciais.

As disputas sobre as melhores formas de gerenciamento da pandemia já vinham ocorrendo desde os primeiros casos registrados no Brasil: de um lado, o governo federal e, em especial, o presidente da República, combatia as diretrizes de isolamento social preconizadas pela OMS como únicas formas de proteção contra o vírus, minava a aplicação de medidas de restrição de mobilidade e de aglomerações e qualificava a doença como uma "gripezinha", além de utilizar termos como "histeria" e "fantasia" para se referir às reações à pandemia (Gripezinha..., 2020); de outro, autoridades de estados e municípios corroboravam e legitimavam a instituição de quarentenas restritivas declarando que continuariam a adotar medidas baseadas no que afirmava a ciência (Turtelli, 2020). O governador de São Paulo, estado com maior número de casos e de mortes no país, afirmou que o conflito com o governo federal "não era apenas político", mas justificava-se pois Bolsonaro era "um antagonista da ciência e da medicina" (Cotrim; Silva, 2020), e afirmou peremptoriamente que "a decisão [de renovar a quarentena no estado] foi amparada pelo Grupo de Contingência da Covid-19, pelos especialistas que nos orientam. Aqui nós não brigamos com a ciência, e a orientação da ciência foi para prorrogar a quarentena", dizendo, ao fim, que "não tomava decisões baseadas na ideologia" (Aqui..., 2020).

Gradualmente, entretanto, a defesa intransigente da ciência conjugada à refutação das "decisões baseadas na ideologia" foi acomodando demandas pela reabertura do comércio de rua, shoppings, academias e outros serviços considerados não essenciais. A quarentena, cujo pilar de fundamentação lógica era o isolamento de pessoas saudáveis para que estas não servissem de vetor de transmissão do vírus e, em decorrência disso, houvesse sobrecarga do sistema de saúde, foi ganhando nuances e gradações capazes de dialogar com determinadas métricas que pudessem corroborar as flexibilizações propostas: a taxa de ocupação dos leitos de UTI; as novas formas de avaliação, como a chamada média móvel de novos casos e de novas mortes; o suposto atraso na comunicação de determinadas mortes pela demora na entrega de resultados de testes; e, ainda, a justificativa de que os aumentos dos casos e mortes estavam associados a um aumento da capacidade de testagem, e não a um aumento 
da transmissibilidade. Em alguns casos, a substituição das autoridades públicas de saúde por aquelas responsáveis pela gestão da política econômica em entrevistas coletivas e em processos de tomada de decisão tornou-se frequente (como no caso das coletivas de imprensa do governo do estado de São Paulo), e a reabertura proposta era vendida como aquela que seguia "todos os protocolos de segurança" e se dava em razão de uma estabilização da doença verificável em indicadores estatísticos que eram aferidores da realidade concreta da pandemia sob essa perspectiva.

Assim, diante de uma estabilidade que cronificava a perda diária de mais de mil vidas no país, tornou-se comum associar a crítica aos planos de reabertura a uma reação psicológica que não se ancorava nos índices de imanência da realidade. Os detratores dos planos de reabertura e defensores da quarentena viam-se repentinamente descontinuados da concretude de números que, supostamente, retratavam um mundo incapaz de ancorar o medo de sair de casa. Era, nas palavras de Kohn (2013, p. 49, tradução minha), o pensamento simbólico "correndo solto" e criando mentes "radicalmente separadas da base indexical que seus corpos poderiam fornecer". A experimentação do medo torna-se, assim, uma elaboração alucinatória diante de um mundo em que tal medo não resistia ao teste empírico: caso os defensores da quarentena fossem menos "pessimistas" e mais "realistas", caso se despissem das lentes ideológicas matizantes da realidade de maneira a enxergá-la como ela, de fato, era, e não como acreditam ou gostariam que fosse, eles perceberiam a realidade "para além de nossas meras ficções humanas" (Stengers, 2005, p. 185, tradução minha). O polo privilegiado de definição do real e do mundo comum possível estava, assim, nas mãos do Estado, enquanto metáfora obviada de João Doria, amparado no conhecimento científico tido como axiologicamente neutro e imaginado como desimplicado nas lutas ideológicas mundanas da política.

A maneira como são descritas as pessoas teoricamente acometidas pela síndrome da cabana é exemplar dessa asserção. Em uma das primeiras matérias jornalísticas sobre o tema no Brasil, publicada ainda em maio (Nardelli, 2020), a manchete diz "entenda por que há quem não queira o fim do isolamento", alocando essa posição na esfera do desejo pessoal. A reportagem prossegue dizendo que, a despeito de o isolamento ter causado sofrimento nos primeiros dias, ele passou a ser prazeroso. Uma personagem imaginada fala "para que sair se posso fazer compras, trabalhar, treinar e até mesmo me divertir dentro 
de casa, num ambiente acolhedor e livre de riscos?" como exercício retórico ilustrativo dos questionamentos de quem deseja ficar em casa mesmo ao fim da pandemia. Por fim, diagnostica que "se você faz parte desse time que sente calafrios só de imaginar o retorno para a civilização pós-pandemia, talvez seja mais uma das vítimas da síndrome da cabana", aludindo a uma "civilização pós-pandemia" que, em teoria, já existia. Especialistas ouvidos confirmam a existência da síndrome, e um psiquiatra lista os sintomas: falta de motivação e ânimo, alteração de humor, perda de memória e concentração, sensação de frustração e impotência, alteração do sono, distúrbio alimentar e ansiedade, ressaltando que pessoas introvertidas seriam mais suscetíveis a adquirir a condição.

A Empresa Brasil de Comunicação (EBC), agência de notícias ligada ao governo federal, também veiculou reportagem sobre o tema por três vezes. $\mathrm{Na}$ primeira, em junho (Coronavírus..., 2020), diz que a síndrome pode causar medo de voltar à rotina "mesmo usando proteção". Na segunda, em julho (Síndrome..., 2020), a neuropsicóloga ouvida pela reportagem afirma que, após um longo período de isolamento, "o cérebro passa a entender que só em casa estamos seguros", embora reconheça que "o medo" dessas pessoas "é real" - dizer que o medo é real não significa, entretanto, que suas causas o são, ou seja, que há o estímulo externo aferível capaz de desencadear tal medo. A terceira, também em julho (Vitor, 2020), afirma que "o distúrbio ocorre quando a pessoa percebe que ficar em casa é mais vantajoso que sair". Assim, com a pandemia ainda em curso, a síndrome tornava-se artifício de dissimulação de pessoas que, forçadas ao retorno à rotina de trabalho e ao uso do transporte público, por exemplo, na realidade sentiam prazer no isolamento e, por isso, resistiam à reabertura. A máquina estatal, "amparada na ciência" - inclusive naquela de profissionais, como psicólogos e psiquiatras, que referendavam a imanência da condição chamada de síndrome da cabana, inscrita no cérebro das pessoas por ela acometidas (e não há imanência maior no campo da saúde mental do que as neurosinapses) -, afirmava que a reabertura era segura sob determinados protocolos e, portanto, não havia motivo real para resistir a ela ou dizer que ela era nada além de segura.

A crença na irrefutabilidade da ciência enquanto descritora da realidade unívoca do mundo-em-si materializada nos efeitos potencialmente inegáveis da pandemia também embasou os argumentos dos defensores das medidas de isolamento social mais restritivas. O biólogo Atila Iamarino (2020b, grifo meu), que ganhou grande notoriedade durante a pandemia, afirmou que 
"o problema pra quem tenta negar a realidade com a COVID-19 é que ela avança rápido e tem muito país passando pelo problema, além de muito estudo". Em outro momento, enquanto sendo entrevistado no programa Roda Viva (Iamarino, 2020a), da TV Cultura, o biólogo comparou o fenômeno do negacionismo, que classificou como sendo da ordem da narrativa - i.e., da dimensão simbólica acessória à realidade -, nos casos específicos do aquecimento global e da pandemia de Covid-19: enquanto a confrontação da narrativa negacionista do aquecimento global com a realidade, capaz de negar a negação, poderia demorar décadas, aquela relativa à pandemia dar-se-ia em poucas semanas. Atila vaticina: "Quem está negando agora, eu só tenho que sentar e esperar." Nunca, portanto, havíamos visto "uma narrativa sendo confrontada tão rápido com a realidade", que, de tão real, não está sujeita a elucubrações de ordem simbólica, pois é imanente em si mesma e independe de significação para existir. Também aqui se delineia um outro polo privilegiado de produção da realidade, pois a biologia insere-se, dessa forma, em uma dimensão supranarrativa semelhante à física na descrição de Stengers (2005).

Dessa forma, a doença se torna real na mesma medida que seus efeitos são da ordem do mundo-em-si e imune a narrativas. O que Löwy (2006) descreve como o ato de tornar o invisível (em casos de patógenos microscópicos) visível passa por tornar seus efeitos visíveis em descrições acima das narrativas ficcionais das crenças "negacionistas", "acientíficas" e pré ou extramodernas. Assim, as métricas da pandemia e os esforços de construção de indicadores capazes de tornar seus efeitos visíveis por meio de taxas de transmissibilidade e letalidade, de médias móveis e de boletins epidemiológicos de toda sorte são tentativas de estabelecimento de uma realidade não alucinatória, ainda que, no limite, a informação seja, por excelência, incompleta (Caduff, 2014). Os efeitos invisíveis, impreenchíveis pelas informações disponíveis, são, portanto, menos reais e mais alucinatórios, e tornar determinadas métricas índices de realidade acaba por conceder o poder decisório sobre quais mundos existem ou não ao Estado e a determinadas disciplinas da ciência ligadas à apreensão de um mundo-em-si invariável e imune aos processos de simbolização que se lhe aplicam. Se a topografia da subnotificação de casos de Covid-19 é irregular, a invisibilização de contágios e mortes de determinados grupos leva a concretude desse fato à esfera das realidades produzidas enquanto narrativas: não são, portanto, reais - e isso encontra paralelo em uma miríade de outros fenômenos relacionados 
a grupos socialmente marginalizados, como o racismo, a violência policial e tantos outros cuja incidência é maior sobre as populações negras, indígenas, migrantes, refugiadas, femininas, LGBTQI+ e tantas outras.

\section{Conclusão}

O processo de definição da imanência da realidade é um processo política e simbolicamente disputado, e a análise da pandemia de Covid-19 no Brasil permite apontar como a disputa sobre quais de seus efeitos estavam ou não ancorados nos índices concretos do mundo-em-si definiu a gestão estatal da ciência (uma não narrativa), da técnica e das metodologias de mensuração dos efeitos da doença no país. O polo privilegiado de definição do real e do mundo comum possível estava, assim, nas mãos do Estado, amparado no conhecimento científico tido como axiologicamente neutro e imaginado como desimplicado nas lutas ideológicas mundanas da política. As pretensas supranarrativas científicas, apesar de serem, por vezes, antagônicas, raramente abrem mão do lugar, embebido de poder, de definidoras de um mundo-em-si não sujeito às elucubrações de ordem simbólica, mera camada acessória ficcional de uma natureza que se impõe. A disputa, portanto, é para definir quem está alucinando enquanto mira a realidade por meio das lentes matizantes desta ou daquela crença, e quem está percebendo e descrevendo o real.

Assim, a dimensão simbólica não é acessória à imanência da realidade, mas, como argumentou Wagner (2012, 2017), a produz na mesma medida em que é por ela produzida. "A 'estrutura'", nos diz Wagner (2017, p. 173, grifo do autor), "não é definida como determinadora do sentido, mas antes como subsumida". O significado é uma parte da experiência, mas também algo que a experiência constrói; um ambiente em que elementos simbólicos relacionam-se entre si, simultaneamente formado pelo ato de relacioná-los (Wagner, 2012, p. 111). Essa, entretanto, não é uma formulação idealista-ingênua, mas materialista semiótica, nos termos de Haraway (2019): o discurso (ou a narrativa) é mundificante (worlding). Sentar e esperar que a realidade concreta se imponha é abster-se, portanto, da disputa pelo real, que não é um dado do que se imagina ser a natureza: o risco é descobrir-se alucinando sobre um mundo-em-si autoevidente que acabará por nunca ter existido. 


\section{Referências}

'AQUI nós não brigamos com a ciência', diz Doria ao prorrogar quarentena. Estado de Minas, Belo Horizonte, 17 abr. 2020. Disponível em: https://www.em.com.br/app/ noticia/nacional/2020/04/17/interna_nacional,1139613/aqui-nao-brigamos-com-a-ciencia-diz-doria-ao-estender-quarentena.shtml. Acesso em: 23 ago. 2020.

BRANCO-PEREIRA, A. “Mas é só você que vê?": a percepção social da loucura e o processo de reconstrução do universo simbólico do sujeito diagnosticado. 2013. Monografia (Graduação em Ciências Sociais) - Universidade de Brasília, Brasília, 2013.

BRANCO-PEREIRA, A. O refúgio do trauma. Notas etnográficas sobre trauma, racismo e temporalidades do sofrimento em um serviço de saúde mental para refugiados. REHMU: Revista Interdisciplinar de Mobilidade Humana, Brasília, v. 26, n. 51, p. 79-97, 2018. DOI: 10.1590/1980-85852503880005306.

BRANCO-PEREIRA, A. Viajantes do tempo: imigrantes-refugiadas, saúde mental, cultura e racismo na cidade de São Paulo. 2019. Dissertação (Mestrado em Antropologia Social) - Centro de Educação e Ciências Humanas, Universidade Federal de São Carlos, São Carlos, 2019.

BRANCO-PEREIRA, A. Viajantes do tempo: imigrantes-refugiadas, saúde mental, cultura e racismo na cidade de São Paulo. Curitiba: Ed. CRV, 2020a. DOI: 10.24824/978854444061.2.

BRANCO-PEREIRA, A. Autismo e maternidade migrante: psicopatologizando relações em mobilidade. Vivência: Revista de Antropologia, Natal, v. 1, n. 56, p. 21-41, 2020b. DOI: 10.21680/2238-6009.2020vln56ID23676.

BRANCO-PEREIRA, A. Aculturalidade e hiperculturalidade: entre saberes e crenças em um serviço de saúde mental para imigrantes e refugiadas. R@U: Revista de Antropologia da UFSCar, São Carlos, v. 12, n. 1, p. 256-279, 2020 c.

BUNZL, M. Franz Boas and the Humboldtian tradition: from Volksgeist and Nationalcharakter to an anthropological concept of culture. In: STOCKING, G. (ed.). Volksgeist as method and ethic: essays on Boasian ethnography and the German anthropological tradition. Madison: University of Wisconsin Press, 1996. p. 17-78.

CADUFF, C. Sick weather ahead: on data-mining, crowd-sourcing and white noise. The Cambridge Journal of Anthropology, New York, v. 32, n. 1, p. 32-46, 2014. DOI: 10.3167/ca.2014.320104. 
CHIU, L. P. W. Differential diagnosis and management of hallucinations. Journal of the Hong Kong Medical Association, Hong Kong, v. 41, n. 3, p. 292-297, 1989.

CORONAVÍRUS: síndrome pode causar medo de voltar à rotina. 1 vídeo (1min30s). Brasília: TV Brasil, 8 jun. 2020. Disponível em: https://tvbrasil.ebc.com.br/reporter-brasil/2020/06/coronavirus-sindrome-pode-causar-medo-de-voltar-rotina. Acesso em: 24 ago. 2020.

COTRIM, C.; SILVA, M. R. Bolsonaro é antagonista da ciência e da medicina, diz Doria. UOL, São Paulo, 18 maio 2020. Disponível em: https://noticias.uol.com.br/ ultimas-noticias/agencia-estado/2020/05/18/bolsonaro-e-antagonista-da-ciencia-e-da-medicina-diz-doria-em-entrevista.htm. Acesso em: 23 ago. 2020.

DESCOLA, P. As duas naturezas de Lévi-Strauss. Sociologia \& Antropologia, v. 1, n. 2, p. 35-51, nov. 2011.

"GRIPEZINHA" e "histeria": cinco vezes em que Bolsonaro minimizou o coronavírus. Congresso em Foco, Brasília, 1 abr. 2020. Disponível em: https://congressoemfoco. uol.com.br/governo/gripezinha-e-histeria-cinco-vezes-em-que-bolsonaro-minimizou-o-coronavirus/. Acesso em: 23 ago. 2020.

HARAWAY, D. A giant bumptious litter: Donna Haraway on truth, technology, and resisting extinction. Logic, [s. l.], n. 9, 2019. Disponível em: https://logicmag.io/ nature/a-giant-bumptious-litter/. Acesso em: 25 ago. 2020.

HARPER, C. A. et al. Functional fear predicts health compliance in the COVID-19 pandemic. International Journal of Mental Health and Addiction, New York, 2020. DOI: 10.1007/s11469-020-00281-5.

IAMARINO, A. [Entrevista ao programa] Roda Viva, São Paulo, 30 mar. 2020a. 1 vídeo (91min). Disponível em: https://www.youtube.com/watch?v=s00BzYazxvU. Acesso em: 24 ago. 2020.

IAMARINO, A. O problema pra quem tenta negar a realidade com a COVID-19 é que ela avança rápido e tem muito país passando pelo problema, além de muito estudo. São Paulo, 3 jun. 2020b. Twitter: @oatila. Disponível em: https://twitter.com/oatila/status/1268241690608926721. Acesso em: 24 ago. 2020.

KOHN, E. How forests think: toward an anthropology beyond the human. Berkeley: University of California Press, 2013.

LATOUR, B. Waiting for Gaia: composing the common world through arts and politics. [Palestra]. London: French Institute, 2011a. 
LATOUR, B. There is no such thing as a common world: it needs to be composed. Multitudes, Paris, v. 45, n. 2, p. 38-41, 2011b.

LATOUR, B. Another way to compose the common world. HAU: Journal of Ethnographic Theory, Chicago, v. 4, n. 1, p. 301-307, 2014.

LÖWY, I. Tornar o invisível visível: viagens, coletas e análises de laboratório. In: LÖWY, I. Vírus, mosquitos e modernidade: a febre amarela no Brasil entre a ciência e a política. Rio de Janeiro: Ed. Fiocruz, 2006. p. 197-249.

LUHRMANN, T. M. Hallucinations and sensory overrides. Annual Review of Anthropology, Palo Alto, v. 40, p. 71-85, 2011.

NARDELLI, B. Síndrome da cabana: entenda por que há quem não queira o fim do isolamento. Metropóles, Brasília, 31 maio 2020. Disponível em: https://www.metropoles.com/vida-e-estilo/comportamento/sindrome-da-cabana-entenda-por-que-ha-quem-nao-queira-o-fim-do-isolamento. Acesso em: 24 ago. 2020.

PAKPOUR, A.; GRIFFITHS, M. D. The fear of COVID-19 and its role in preventive behaviors. Journal of Concurrent Disorders, Woodbridge, 2020. Preprint.

SETH, A. K. Your brain hallucinates your conscious reality. 1 vídeo (17min). [S. l.]: TED Conferences, 2017. Disponível em: https://www.ted.com/talks/anil_seth_your_ brain_hallucinates_your_conscious_reality. Acesso em: 10 ago. 2020.

SÍNDROME da cabana: quando o medo de sair de casa se transforma em doença. Brasília: EBC Rádio, 10 jul. 2020. Disponível em: https://radios.ebc.com.br/tarde-nacional/2020/07/sindrome-da-cabana-quando-o-medo-de-sair-de-casa-se-transforma-em-doenca. Acesso em: 24 ago. 2020.

STENGERS, I. Introductory notes on an ecology of practices. Cultural Studies Review, Sydney, v. 11, n. 1, p. 183-196, 2005.

TEEPLE, R. C.; CAPLAN, J. P.; STERN, T. A. Visual hallucinations: differential diagnosis and treatment. The Primary Care Companion to The Journal of Clinical Psychiatry, [s. l.], v. 11, n. 1, p. 26-32, 2009. DOI: 10.4088/pcc.08r00673.

TURTELLI, C. Em carta, governadores pedem apoio a Bolsonaro e reafirmam medidas apoiadas na ciência. Estadão, São Paulo, 23 mar. 2020. Disponível em: https:// politica.estadao.com.br/noticias/geral,em-carta-governadores-pedem-apoio-a-bolsonaro-e-reafirmam-medidas-apoiadas-na-ciencia,70003249192. Acesso em: 23 ago. 2020. 
VITOR, D. De volta às ruas, pessoas relatam Síndrome da Cabana e temem qualquer interação. Brasília: Radioagência Nacional, 13 jul. 2020. Disponível em: https:// agenciabrasil.ebc.com.br/radioagencia-nacional/acervo/saude/audio/2020-07/na-volta-ao-convivio-fora-de-casa-pessoas-relatam-sindrome-da-cabana-e-temem/. Acesso em: 24 ago. 2020.

WAGNER, R. A invenção da cultura. São Paulo: Cosac Naify, 2012.

WAGNER, R. Símbolos que representam a si mesmos. São Paulo: Ed. Unesp, 2017.

Recebido: 29/08/2020 Aceito: 20/01/2021 | Received: 8/29/2020 Accepted: 1/20/2021 